\title{
An International Spatial Analysis of Welfare Spending's Influence on Measles
}

\author{
Mary Ellen J. Walker ${ }^{1}$, Michael L. Szafron ${ }^{2} \&$ June M. Anonson ${ }^{3}$ \\ ${ }^{1}$ College of Nursing, University of Saskatchewan, Saskatoon, Canada \\ ${ }^{2}$ School of Public Health, University of Saskatchewan, Saskatoon, Canada \\ ${ }^{3}$ College of Nursing, University of Saskatchewan, Prince Albert, Canada \\ Correspondence: Mary Ellen Walker, 147 LeValley Cove, Saskatoon, SK, S7M 0H6, Canada. Tel: \\ $1-306-231-4532$.
}

Received: July 13, 2021 Accepted: August 10, 2021 Online Published: August 24, 2021

doi:10.5539/gjhs.v13n10p9 URL: https://doi.org/10.5539/gjhs.v13n10p9

\begin{abstract}
Background: National welfare policies have the potential to influence population health. Yet, no research has investigated the influence that welfare spending levels have on primary prevention interventions.

Methods: This study uses generalized linear mixed model Bayesian analysis to explore how welfare spending influences the relationship between measles counts and measles vaccination rates at a national level. Furthermore, models include random effects to account for the nested structure of countries within regions. A conditional autoregressive model was also developed to test for the influence of spatial relationships among the variables of interest.

Results: Analysis of the Bayesian Information Criterion (BIC) indicated that the non-spatial model $(\mathrm{BIC}=19743.090)$ was preferred over the spatial model $(\mathrm{BIC}=24225.730)$. The final model found that both the first dose of measles vaccine $(B=-0.835,95 \% C r$. $I .=-0.975,-0.699)$, public social protection $(B=-0.936,95 \% \mathrm{Cr}$. $\mathrm{I} .=-1.132,-0.744)$, and their interaction $(\mathrm{B}=-0.239,95 \%$ Cr. I. $-0.319,-0.156)$ had a negative influence on national measles counts.
\end{abstract}

Conclusions: This finding indicates that welfare spending may enhance primary prevention interventions, like measles vaccination.

Keywords: bayesian analysis, immunization, measles, prevention, welfare spending

\section{An International Spatial Analysis of Welfare Spending's Influence on Measles}

National policies are important in shaping people's lives and have implications for their health (Jorm \& Ryan, 2014). Welfare policies are an example of national policies that have a role in shaping national political environments and impact people throughout their lives (Ferrarini, 2006). Therefore, it is important to understand how welfare policies may impact health. Some theorists have asserted that welfare policies have their influence through socializing risk and providing equal opportunities (Esping-Andersen, 1990; Esping-Andersen, 2009). Exploring the ways in which national welfare policies influence health is important in understanding the impact of such policies on peoples' lives.

Previous research exploring the influence of welfare policies on health has unearthed some important findings. Research has indicated that countries that are increasingly egalitarian show improved population health outcomes (Ng, Muntaner, \& Chung, 2016). For example, social democratic welfare states are considered the most redistributive and have the lowest infant mortality rates (Raphael, 2013). In addition, liberal welfare states are considered the least redistributive and have the highest infant mortality rates (Raphael, 2013). Furthermore, welfare policy research has found that social democratic welfare states promote better women's health (Borrell et al., 2014), and poor self-reported health is less likely among the unemployed in countries with high levels of welfare benefits (Shahidi, Siddiqi, \& Muntaner, 2016). These studies have helped to uncover the impact of welfare policies on health. However, there are areas of research that remain unexplored.

Few researchers have investigated how welfare policies influence the outcomes of health interventions, like immunizations. Of the research that explores welfare policies related to immunizations, most only use descriptive 
statistics to explore variables. In fact, in an extensive literature review, Daku, Raub, and Heymann (2012) were the only researchers to publish an article that used statistical inference to explore countries' maternity leave benefits in relation to childhood immunization rates. They found that maternity leave length and income replacement have a positive relationship with childhood immunization rates. However, this study focused on one specific type of welfare benefit rather than a comprehensive indicator of welfare benefits.

A country's spending on welfare benefits and services may have implications for how people respond to preventative health interventions. Immunizations are preventative health interventions that can have serious implications for individual and national health. However, little research has focused on welfare policies' influence on immunizations and their outcomes. Measles immunization is an important preventative health intervention to study because of its high level of infectiousness, recent outbreaks, and inclusion as an international health priority (United Nations, 2015). Furthermore, countries with similar welfare policies are often located near to each other (Esping-Andersen, 1990; Esping-Andersen, 2009); yet, limited welfare policy research has explored the impact of geography on these relationships. Therefore, spatial analytic methods are an important consideration in exploring relationships between measles and welfare spending. This research will account for significant spatial relationships while exploring national welfare spending's influence on the relationship between national measles immunizations rates and national measles cases.

\section{Variables and Selection of Measurement Methods}

\subsection{Welfare Spending}

To examine national welfare spending, this study looks specifically at public social protection (PSP) expenditure as a proportion of gross domestic product (GDP). PSP is commonly used to represent the share of resources distributed according to social criteria, rather than market criteria (Esping-Andersen, 1990). PSP represents spending to reduce and prevent poverty, vulnerability, and social exclusion, including child and family benefits, maternity protection, unemployment support, employment injury benefits, sickness benefits, health protection, old-age benefits, disability benefits, and survivors' benefits (International Labour Organization, 2017). PSP expenditure as a proportion of GDP was obtained from the International Labour Organization (2017), with data available for most countries in the years 1995, 2000, 2005, and 2010 to 2015. Therefore, this research will use PSP measures over time to represent welfare spending.

\subsection{Measles}

The reported number of measles is available from the World Health Organization (2016). The number of measles cases will be standardized by population size with national population counts of the same year (The World Bank Group, 2017b). The measles immunization series consists of a measles-containing vaccine first-dose and second-dose. We define the variable MCV1 as the percentage of children, age one year, who have received one dose of measles vaccine in a given year (World Health Organization, 2017); and MCV2 as the percentage of children who have received their second dose of measles vaccine according to nationally recommended standards (The World Bank Group, 2017b).

\subsection{Control Variables}

We have carefully selected control variables to account for possible influence on the relationship between welfare spending and measles immunization. We controlled for world region by categorizing countries according to the United Nations (2017) geographical regions, which may account for any region-specific influences on health policies, social policies, or health outcomes. Defamilialization represents women's lack of dependency on the family for social protection (Esping-Andersen, 1999). We used female employment rates as a proxy for defamilialization because employment gives women greater independence. Female employment rate represents the proportion of the female population aged 15 and above who participate in the labor force, retrieved from The World Bank Group (2017a). Democracy has an important role in the determination of how resources are distributed among a population. Therefore, the Polity IV democracy index from the Center for Systemic Peace (2017) represents democracy in a given country. The Polity IV is based on scoring countries according to democratic and authoritarian principles related to elections, the transition of power after elections, constraints on the chief executive of the state, political participation, and competition between political parties (Marshall, Gurr, \& Jaggers, 2017). This study will also include the Gini index, representing country income inequality. Gini index values range from zero, representing perfect equality, to 100, representing perfect inequality (The World Bank Group, 2017b). Finally, GDP per capita will control for the overall level of development in a country, and it is available from The World Bank Group (2017b). 


\section{Methods}

\subsection{Sample}

The sample for this study includes all countries for which data is available for at least one year for PSP expenditure, MCV1, MCV2. Data includes the years 1995, 2000, 2005, 2010-2015, as these are the years that PSP data was collected. The final sample for analysis includes 157 countries.

\subsection{Statistical Analysis}

Once the final dataset was collected, means, standard deviations, relative frequencies, and scatter plots were used to summarize the data, and Moran's I test for global spatial autocorrelation was used to test for spatial autocorrelation in the variables of interest.

Prior to beginning modelling, we found that there were missing values in the dataset. Therefore, these missing values were replaced with Markov Chain Monte Carlo simulations using predictive mean modeling in SPSS (IBM Corporation, 2016). Nine simulations were created. Initial analysis was completed separately with all nine imputations to determine if the imputed data was having an influence on the results. The analyses from each of the nine datasets were found to have results that lied within each other's confidence intervals. Therefore, only one imputed dataset was used to report results and run the final Bayesian models (discussed below).

\subsubsection{Model Building}

Generalized linear mixed model (GLMM) regression was applied to the data. GLMMs can account for variables that have non-normal distributions and variables that are correlated (IBM Corporation, 2012). GLMMs allowed us to account for the correlation between countries that lie within the same world region and had repeated measures of data by year. Initially, univariate negative binomial models were computed in SAS studio (SAS Institute Inc., 2020) between the dependent variable and each independent or control variable. In these models, the dependent variable was measles counts in a country within a given year. The model offset was the population size of the country within the same year.

Most of the independent variables needed to be transformed to converge into a univariate model. GDP, GINI, MCV1, MCV2, and PSP variables were transformed with the natural log and standardized. The natural $\log$ transformation and standardization preserve the relationships among the variables because the order of the data from smallest to largest values does not change. However, the degree of difference between data points may have changed. Hence, these transformations and the purpose of the research must be considered when interpreting the results. The purpose of this research is to explore relationships among variables, and not to make predictions. Therefore, the interpretation of these results focuses on the direction of the relationship, rather than the exact coefficient result. The Polity coefficient was not transformed because statistical programs were able to output models based on the Polity coefficient in its natural form. All of the model coefficients were converted to standardized beta coefficients so that the independent variables' associations with the dependent variable were comparable.

In the univariate models, coefficient estimates that had a p-value of 0.20 or less were included in the multivariate fixed-intercept model. For the multivariate model, interactions were tested between the variables of interest (MCV1, MCV2, and PSP) and reported if they were significant at 0.05 . Then, a multivariate model with random intercepts for countries and world regions was computed. The significance level for interpreting these models was set with $\alpha=0.05$. Models were compared with the Bayesian Information Criterion (BIC), the $-2 \log$ likelihood $(-2 \mathrm{LL})$ value, and how additional variables and random intercepts impacted the overall model. Once multivariate random-intercept models were completed based on frequentist statistics methods, parameters and random effects were re-examined with Bayesian statistics in OpenBUGS (Spiegelhalter, Thomas, Best, \& Lunn, 2014).

\subsubsection{Bayesian Analysis}

In the multivariate Bayesian model, random effects were included for country $(u)$ and world region $(v)$. In the spatial model, a random effect for spatial error was also added $(s p)$. All parameters and random effects were estimated with non-informative priors that were set to a normal distribution with a mean of zero and a variance of 0.001. The spatial random effect was modeled with a Gaussian conditional autoregressive (CAR) distribution. The Gassian CAR model allowed countries to be defined as neighbors, which is appropriate for spatially distributed random effects (Spiegelhalter et al., 2014). The spatial precision was structured with a gamma distribution having a mean of 0.5 and a variance of 0.0005 . The non-spatial model had the following for the country $i$ :

$$
\ln \left(y_{i}\right)=\ln \left(P O P_{i}\right)+\alpha+\beta_{1} X_{1}+\beta_{2} X_{2}+\cdots+\beta_{m} X_{m}+u+v .
$$

The spatial model had the following for the department $i$ : 


$$
\ln \left(y_{i}\right)=\ln \left(P O P_{i}\right)+\alpha+\beta_{1} X_{1}+\beta_{2} X_{2}+\cdots+\beta_{m} X_{m}+u+v+s p .
$$

In these models, the population $\left(P O P_{i}\right)$ was the offset, $\alpha$ represented the intercept, and the betas $\left(\beta_{1}, \beta_{2}, \ldots \beta_{\mathrm{m}}\right)$ represented the coefficient estimates for the independent variables $\mathrm{X}_{1}, \mathrm{X}_{2}, \ldots \mathrm{X}_{\mathrm{m}}$. The exponentiated value of ( $\ln$ $\left.\left(y_{i}\right)-\ln \left(P O P_{i}\right)\right)$ represents the measles rate in a country each year.

To run the Bayesian models, a burn-in period ( $\mathrm{T}=175,000$ time-steps) was selected based on Brook-Gelman-Rubin plots (Gelman \& Rubin, 1992). The time between independent sample was 17,500 (burn-in period/10). To ensure that the burn-in period did not have undue influence on the estimates, the length of the simulation was set such that the burn-in period would be five percent of the total length of run and increased until convergence was confirmed ( $\mathrm{T}=20,020,000$ time-steps). This provided 1144 data-points with independent samples every 17,500 time-steps for each of three chains. To confirm that chains had converged and were sampling from stationary distributions, convergence diagnosis and output analysis (CODA) data were analyzed with R Studio software package (RStudio Team, 2016). The Gelman and Rubin (1992), Geweke (1992), Raftery and Lewis (1992), and Heidelberger and Welch (1981) tests were the diagnostics performed.

\subsubsection{Spatial Models}

We used spatial testing to determine if neighbouring countries' welfare spending might impact measles outcomes in a given country, i.e. if spatial correlation exists amongst the residuals in the non-spatial model. These spatial tests justified the development of a GLMM that included a spatial random effect (as discussed above). The spatial analysis was used to determine if the influence of welfare spending on measles immunizations and disease rates is more alike in countries that are geographically close to one another than those that are far apart.

To conduct spatial analysis, the relation between countries must be defined with a neighborhood matrix. Various neighborhood matrices were considered, including defining neighbors based on shared borders or distance from a country's centroid. However, we used a neighborhood matrix based on contiguity, but it was altered to include countries separated by $200 \mathrm{~km}$ or less by water as neighbors. This neighborhood matrix was used to structure the spatial error in the Bayesian model with spatial random effects. Model selection between the Bayesian models with and without spatial effects was based on the BIC value.

\section{Results}

\subsection{Descriptive Results}

Initial testing of the data was completed with non-parametric Friedmans' analysis of variance (ANOVA) and descriptive statistics (see table 1). Friedman's ANOVA tests revealed that there were significant differences between regions based on measles rates $(\chi=1142.1, \mathrm{df}=1040, \mathrm{p}$-value $=0.014), \mathrm{MCV} 1(\chi=209.78, \mathrm{df}=69$, $\mathrm{p}$-value $<0.001)$ and $\operatorname{MCV} 2(\chi=148.80, \mathrm{df}=80, \mathrm{p}$-value $<0.001)$. Interestingly, there was not a significant difference between regions based on PSP $(\chi=985.86, \mathrm{df}=966$, $\mathrm{p}$-value $=0.321)$.

Table 1. Descriptive statistics for main variables of interest

\begin{tabular}{llllllllll}
\hline & & N & Missing & Mean & Median & Std. Dev. & Variance & Min & Max \\
\hline \multirow{2}{*}{ Africa } & 424 & 17 & 4827.2 & 213.5 & 188744.1 & 356232834.4 & 0.0 & 212183.0 \\
& Americas & 294 & 3 & 42.3 & 0.0 & 189.5 & 35892.4 & 0.0 & 2631.0 \\
$\begin{array}{l}\text { Measles } \\
\text { count }\end{array}$ & Asia & 370 & 17 & 4163.7 & 206.5 & 12527.6 & 156940951.7 & 0.0 & 124219.0 \\
& Europe & 301 & 32 & 938.2 & 20.0 & 4331.1 & 18758646.1 & 0.0 & 54239.0 \\
& Oceania & 58 & 14 & 315.5 & 0.0 & 1093.2 & 1195051.9 & 0.0 & 7135.0 \\
& All data & 1447 & 83 & 2695.6 & 36.0 & 12344.6 & 152389989.9 & 0.0 & 212183.0 \\
\hline \multirow{2}{*}{$\begin{array}{l}\text { Measles } \\
\text { rate per } \\
\begin{array}{l}100,000 \\
\text { people }\end{array}\end{array}$} & Africa & 420 & 21 & 25.1 & 2.1 & 73.9 & 5459.3 & 0.0 & 782.7 \\
& Americas & 294 & 3 & 0.2 & 0.0 & 1.0 & 1.0 & 0.0 & 11.6 \\
& Oceania & 58 & 14 & 38.3 & 0.6 & 151.0 & 22811.3 & 0.0 & 1008.1
\end{tabular}




\begin{tabular}{llllllllll}
\hline \multirow{4}{*}{ MCV1 } & Africa & 432 & 9 & 79.7 & 85.0 & 17.3 & 297.7 & 19.0 & 99.0 \\
& Americas & 294 & 3 & 91.5 & 93.5 & 9.0 & 81.5 & 32.0 & 99.0 \\
& Asia & 380 & 7 & 90.8 & 95.0 & 11.2 & 125.5 & 27.0 & 99.0 \\
& Europe & 310 & 23 & 92.2 & 94.0 & 8.2 & 68.0 & 50.0 & 99.0 \\
& Oceania & 68 & 4 & 81.8 & 85.0 & 14.5 & 209.5 & 39.0 & 99.0 \\
& All data & 1484 & 46 & 87.6 & 93.0 & 13.7 & 188.1 & 19.0 & 99.0 \\
\hline \multirow{4}{*}{ MCV2 } & Africa & 103 & 338 & 75.3 & 84.0 & 25.1 & 630.7 & 3.0 & 99.0 \\
& Americas & 172 & 125 & 81.4 & 88.0 & 16.9 & 285.6 & 11.0 & 99.0 \\
& Asia & 267 & 120 & 86.7 & 95.0 & 19.0 & 361.2 & 9.0 & 99.0 \\
& Europe & 233 & 100 & 90.5 & 93.0 & 11.5 & 131.8 & 0.0 & 99.0 \\
& Oceania & 38 & 34 & 78.2 & 85.0 & 20.3 & 412.5 & 9.0 & 99.0 \\
& All data & 813 & 717 & 84.8 & 92.0 & 18.5 & 340.5 & 0.0 & 99.0 \\
\hline \multirow{4}{*}{ PSP } & Africa & 204 & 237 & 4.6 & 3.9 & 3.0 & 9.2 & 0.3 & 16.3 \\
& Americas & 174 & 123 & 8.9 & 7.1 & 5.0 & 25.2 & 1.1 & 19.3 \\
& Asia & 275 & 112 & 6.0 & 4.1 & 5.3 & 28.5 & 0.1 & 24.2 \\
& Europe & 289 & 44 & 20.8 & 20.7 & 4.9 & 23.9 & 9.3 & 31.7 \\
& Oceania & 51 & 21 & 9.5 & 7.6 & 7.0 & 49.4 & 0.9 & 22.9 \\
& All data & 993 & 537 & 10.7 & 8.2 & 8.2 & 67.9 & 0.1 & 31.7 \\
\hline
\end{tabular}

Spatial autocorrelation statistics focused on the main variables of interest: measles rates, MCV1, and PSP. Table 2 indicates that measles rates had significant global spatial clustering in the years $1995(\mathrm{I}=0.086, \mathrm{p}$-value $=0.038)$, $2014(\mathrm{I}=0.236$, p-value $=0.006)$, and $2015(\mathrm{I}=0.219$, $\mathrm{p}$-value $=0.002)$, while MCV1 and PSP had significant global spatial clustering in all years. Therefore, these results justify the use of models with spatial error.

Table 2. Spatial cluster results for each year of data analyzed.

\begin{tabular}{lcccccc}
\hline & \multicolumn{2}{c}{ Measles rate } & \multicolumn{2}{c}{ MCV1 } & \multicolumn{2}{c}{ PSP } \\
\cline { 2 - 7 } & Moran's I & p-value & Moran's I & p-value & Moran's I & p-value \\
\hline 1995 & 0.086 & 0.038 & 0.330 & 0.002 & 0.732 & 0.002 \\
2000 & 0.026 & 0.062 & 0.535 & 0.002 & 0.752 & 0.002 \\
2005 & 0.034 & 0.120 & 0.378 & 0.002 & 0.755 & 0.002 \\
2010 & -0.010 & 0.438 & 0.127 & 0.014 & 0.730 & 0.002 \\
2011 & 0.062 & 0.076 & 0.185 & 0.004 & 0.702 & 0.002 \\
2012 & 0.012 & 0.090 & 0.227 & 0.002 & 0.655 & 0.002 \\
2013 & 0.044 & 0.162 & 0.273 & 0.002 & 0.606 & 0.002 \\
2014 & 0.236 & 0.006 & 0.303 & 0.002 & 0.599 & 0.002 \\
2015 & 0.219 & 0.002 & 0.274 & 0.002 & 0.652 & 0.002 \\
\hline
\end{tabular}

\subsection{Fixed-intercept Models}

Negative binomial fixed-intercept models were initially computed. Univariate models for each independent variable and control variable indicated that the MCV1 $(B=-0.42$, $p$-value $<0.001)$, MCV2 $(B=-0.19, p$-value $=$ 0.005), PSP ( $\mathrm{B}=-0.44$, $\mathrm{p}$-value $<0.001)$, GINI $(\mathrm{B}=0.27$, $\mathrm{p}$-value $=0.001)$, GDP $(\mathrm{B}=-0.35$, $\mathrm{p}$-value $<0.001)$, and POLITY $(B=-0.04$, $p$-value $=0.007)$ variables should be included in the fixed-intercept multivariate model (see Table 3). The interaction between PSP and MCV1 was added to the model to explore PSP's influence on the relationship between measles cases and measles immunization rates. 
Table 3. Coefficient estimates from bivariate negative binomial models of independent variables and control variables. Coefficients with a p-value of $<0.20$ were included in the overall model

\begin{tabular}{llllllll}
\hline & $\begin{array}{l}\text { Coefficient } \\
\text { Estimate }\end{array}$ & $\begin{array}{l}\text { Standard } \\
\text { Error }\end{array}$ & DF & t-value & p-value & \multicolumn{2}{c}{ Confidence Limits } \\
\hline FLF & 0.05 & 0.07 & 1413 & 0.69 & 0.493 & -0.09 & 0.18 \\
GDP & -0.35 & 0.06 & 1413 & -6.01 & $<0.001$ & -0.47 & -0.24 \\
GINI & 0.27 & 0.08 & 1413 & 3.29 & 0.001 & 0.11 & 0.43 \\
MCV1 & -0.42 & 0.06 & 1413 & -6.52 & $<0.001$ & -0.55 & -0.30 \\
MCV2 & -0.19 & 0.07 & 1413 & -2.81 & 0.005 & -0.33 & -0.06 \\
POLITY & -0.04 & 0.01 & 1413 & -2.72 & 0.007 & -0.06 & -0.01 \\
PSP & -0.44 & 0.06 & 1413 & -7.08 & $<0.001$ & -0.56 & -0.32 \\
\hline
\end{tabular}

\subsection{GLMM}

Random intercepts were added to the multivariate model. Models were computed with random intercepts for countries only, world region only, and with countries being nested within world regions. This process was repeated for each of the nine imputed data sets (discussed above), and results from the final model were compared. None of the coefficient estimates for each of the nine models differed in direction and confidence intervals overlapped between all nine models. Therefore, only results from the first imputation are displayed (see Table 4).

Table 4. Multivariate models

\begin{tabular}{|c|c|c|c|c|c|c|c|c|c|c|c|c|c|}
\hline & Intercept & MCV1 & MCV2 & GDP & GINI & PSP & POLITY & MCV1*PSP & Country & Region & Error & $\mathrm{BIC}$ & $-2 \mathrm{LL}$ \\
\hline Model 1 & $-9.09^{+}$ & $-0.48^{+}$ & $0.22^{\dagger}$ & -0.18 & -0.14 & $-0.48^{+}$ & 0.03 & & & & $5.92^{+}$ & 17852 & 17794 \\
\hline Model 2 & $-9.07^{\dagger}$ & $-0.61^{+}$ & $0.22^{+}$ & $-0.24^{\dagger}$ & $-0.24^{\dagger}$ & $-0.53^{+}$ & $0.03^{+}$ & $-0.28^{+}$ & & & $5.83^{+}$ & 17831 & 17765 \\
\hline & $-10.13^{\dagger}$ & $-0.92^{+}$ & $0.22^{+}$ & $-0.59^{\dagger}$ & & $-0.68^{+}$ & -0.04 & $-0.24^{+}$ & & & $3.75^{+}$ & 17387 & 17337 \\
\hline & $-9.72^{+}$ & $-0.59^{+}$ & $0.21^{+}$ & -0.08 & 0.04 & $-0.45^{+}$ & $0.05^{+}$ & & & 2.83 & $5.18^{+}$ & 17595 & 17578 \\
\hline Model 5 & $-10.13^{+}$ & $-0.92^{+}$ & $0.23^{+}$ & $-0.59^{\dagger}$ & -0.15 & $-0.67^{\dagger}$ & -0.04 & $-0.24^{\dagger}$ & 1.90 & 1.86 & $3.75^{+}$ & 17392 & 17336 \\
\hline
\end{tabular}

Table includes a fixed model (model 1), a fixed model with an interaction term (model 2), a model with random intercepts for country (model 3), a model with random intercepts for region (model 4), and a model with random intercepts for country nested within region (model 5). ${ }^{\dagger}=$ significant at 0.05 .

The country-only random intercept model showed that the random intercept was significant $(u=3.76, p$-value $<$ $0.001)$, but the region-only random intercept model showed that the random intercept was not significant $(\mathrm{v}=2.83$, $\mathrm{p}$-value $=0.194$ ). The model with random intercepts for country and region showed that both random intercepts had an overall positive influence on the fixed intercept, but both were not significant $(u=1.90, p$-value $=0.233 ; \mathrm{v}$ $=1.86, \mathrm{p}$-value $=0.242$ ). The model with random intercepts for country and region was chosen as the preferred model because it showed a reduction in the unexplained error due and had the lowest BIC value. Furthermore, the addition of region as a random intercept changed the relationship that country had as a random intercept with measles cases. Therefore, we chose model 5 (see table 4) to check with Bayesian methods in OpenBUGS and test for a spatial relationship.

\subsection{Bayesian Models}

The final frequentist model was reassessed with Bayesian methods in OpenBUGS. Convergence analysis of the Bayesian model satisfied criteria suggesting that the three Markov chains had reached their stationary distributions and the samples from these chains were sufficient. The Gelman and Rubin (1992) diagnostic test showed that the potential scale reductions estimated for the models were below 1.05, indicating that the simulations emerged from a stationary distribution. The Raftery and Lewis (1992) diagnostic showed that the run-length was sufficient, as the dependence factor values were lower than 5. The p-values in Geweke (1992) and Heidelberger and Welch (1981) tests were greater than 0.05 for $95 \%$ of the coefficient estimates and random intercepts that significantly differed from zero. 


\subsubsection{Final Spatial and Non-spatial Bayesian Models}

Once the non-spatial Bayesian model was developed, residuals were obtained and tested for spatial clustering. Global spatial clustering was significant in the years $1995(\mathrm{I}=0.099$, p-value $=0.038), 2010(\mathrm{I}=0.161, \mathrm{p}$-value $=$ $0.004), 2013(\mathrm{I}=0.017$, $\mathrm{p}$-value $=0.002), 2014(\mathrm{I}=0.184$, $\mathrm{p}$-value $=0.004)$, and $2015(\mathrm{I}=0.245, \mathrm{p}$-value $=0.002)$. Since more than half of the years studied showed significant spatial clustering, a spatial model was developed with a neighborhood matrix (described above) through a Gaussian CAR model (see Table 5). The spatial random effects were not included in the final model because the Bayesian Information Criterion (BIC) was higher in the spatial model $(\mathrm{BIC}=24225.730)$ than the non-spatial model $(\mathrm{BIC}=19743.090)$. Therefore, the model that does not account for spatial effects was chosen as the final model for interpretation (also see Table 5).

Table 5. Coefficient estimates and variance partition coefficients for model without spatial effects and with CAR normal spatial effects

\begin{tabular}{|c|c|c|c|c|c|c|c|c|}
\hline Model & Variables & $\begin{array}{l}\text { Standardized } \\
\text { coefficients }\end{array}$ & $\begin{array}{l}\text { Coefficient } \\
\text { estimates }\end{array}$ & $\mathrm{sd}$ & MC_error & val2.5pc & median & val97.5pc \\
\hline \multirow{16}{*}{ Non-spatial } & Intercept & & -10.220 & 1.613 & 0.054 & -13.320 & -10.250 & -6.752 \\
\hline & GDP & -297.796 & -1.319 & 0.186 & 0.003 & -1.694 & -1.314 & -0.966 \\
\hline & GINI & 16.174 & 0.159 & 0.084 & 0.001 & -0.003 & 0.158 & 0.321 \\
\hline & MCV1 & -70.284 & -0.835 & 0.069 & 0.001 & -0.975 & -0.834 & -0.699 \\
\hline & MCV1*PSP & -12.181 & -0.239 & 0.042 & 0.001 & -0.319 & -0.240 & -0.156 \\
\hline & MCV2 & 14.001 & 0.202 & 0.057 & 0.001 & 0.090 & 0.202 & 0.313 \\
\hline & POLITY & -1.173 & -0.065 & 0.015 & 0.000 & -0.094 & -0.064 & -0.036 \\
\hline & PSP & -111.291 & -0.936 & 0.098 & 0.002 & -1.132 & -0.935 & -0.744 \\
\hline & VPC error* & & 0.027 & & & & & \\
\hline & VPC country* & & 0.396 & & & & & \\
\hline & VPC region* & & 0.577 & & & & & \\
\hline & VPC error** & & 0.995 & & & & & \\
\hline & VPC country** & & 0.002 & & & & & \\
\hline & VPC region** & & 0.003 & & & & & \\
\hline & $-2 \mathrm{LL}$ & & 18510.000 & & & & & \\
\hline & BIC & & 19743.090 & & & & & \\
\hline \multirow{13}{*}{$\begin{array}{l}\text { Spatial } \\
\text { CAR Normal }\end{array}$} & alpha & & -10.410 & 1.220 & 0.152 & -13.870 & -10.210 & -8.488 \\
\hline & GDP & & -1.365 & 0.187 & 0.008 & -1.748 & -1.366 & -1.007 \\
\hline & GINI & & 0.143 & 0.079 & 0.004 & -0.006 & 0.141 & 0.295 \\
\hline & MCV1 & & -0.833 & 0.070 & 0.003 & -0.970 & -0.835 & -0.698 \\
\hline & MCV1*PSP & & -0.239 & 0.041 & 0.002 & -0.318 & -0.239 & -0.162 \\
\hline & MCV2 & & 0.208 & 0.056 & 0.002 & 0.095 & 0.210 & 0.313 \\
\hline & POLITY & & -0.064 & 0.015 & $5.824 \mathrm{E}-04$ & -0.092 & -0.064 & -0.038 \\
\hline & PSP & & -0.949 & 0.100 & 0.004 & -1.144 & -0.951 & -0.758 \\
\hline & VPC error* & & 0.221 & & & & & \\
\hline & VPC country* & & 0.396 & & & & & \\
\hline & VPC region* & & 0.172 & & & & & \\
\hline & VPC spatial* & & 0.211 & & & & & \\
\hline & VPC error** & & 0.997 & & & & & \\
\hline
\end{tabular}




$\begin{array}{ll}\text { VPC country** } & 0.001 \\ \text { VPC region** } & 0.001 \\ \text { VPC spatial** } & 0.001 \\ \text {-2LL } & 18510.000 \\ \text { BIC } & 24225.730\end{array}$

\footnotetext{
* Calculation based on mean precision values. ${ }^{*}$ Calculation based on median precision values.
}

Our results show that all variables included in the model were significant, except the Gini coefficient (B [unstandardized coefficient] $=0.159 ; 95 \%$ Cr. I. $=-0.003,0.321, \beta$ [standardized coefficient] $=16.174)$. As expected, MCV1 has a negative impact on $\log$ measles count $(\mathrm{B}=-0.835 ; 95 \%$ Cr. I. $=-0.975,-0.699 ; \beta=-70.284)$ However, MCV2 has an unexpected positive relationship with $\log$ measles count $(\mathrm{B}=0.202 ; 95 \% \mathrm{Cr}$. I. $=0.090$, $0.313 ; \beta=14.001)$. Furthermore, our model indicates that PSP has a negative relationship with log measles count $(B=-0.936 ; 95 \%$ Cr. I. $=-1.132,-0.744 ; \beta=-111.291)$. When the negative influence of both MCV1 and PSP on log measles count are taken into consideration with their significant, negative interaction $(\mathrm{B}=-0.239 ; 95 \% \mathrm{Cr}$. $\mathrm{I}$. $-0.319,-0.156 ; \beta=-12.181)$, our results indicate that welfare spending may have a modifying effect on the relationship between measles vaccination and log measles count. In other words, for every unit increase in PSP, the coefficient representing the relationship between MCV1 and log measles count decreases.

In addition, GDP and Polity were significant control variables. GDP had a significant negative influence on log measles count $(\mathrm{B}=-1.219 ; 95 \% \mathrm{Cr}$. $\mathrm{I} .=-1.694,-0.966 ; \beta=-297.796)$ with a relatively large influence on the model compared to the other variables' standardized beta coefficients. Interestingly, Polity's significant and negative relationship with $\log$ measles count $(B=-0.065 ; 95 \%$ Cr. $\mathrm{I}$. $=-0.094,-0.036 ; \beta=-1.173)$ had comparatively very little influence on measles rates when considering the standardized beta coefficient. These results indicate that PSP and MCV1, along with their interaction have negative relationships with measles counts, but GDP's negative relationship with measles rates may be the most influential.

The random effects in the final model are meant to account for the variability that comes from each country and region. It was important to include them in the final model to account for the nested structure of the data and the similarity of data points within the same country or region. These random intercepts allowed the years of data to be more representative of the underlying population. However, the random intercepts' significance in the final model is difficult to interpret. The mean value for the error's precision lied outside its credible interval, indicating that there were some extreme outliers in the precision samples. Therefore, Variance Partition Coefficients (VPC) were calculated based on the mean and median precision for the random error, error explained by country effects, and error explained by region effects. The VPC values calculated based on the mean precisions indicate that country and region may explain a large amount of the variation in the model error. However, the VPC values calculated based on the median indicate that country and region may explain a very small amount of the model error. The VPC values based on median precision values are in agreement with the frequentist models. Due to the extreme outliers found in the precision, we interpreted results based on the median precision value because it is more representative of the center of the distribution of errors.

\section{Discussion}

This study provides evidence to suggest that national welfare policies may play an important role in enhancing primary prevention interventions, like immunizations. These findings suggest that greater levels of welfare spending may have a positive effect on the outcomes of primary prevention interventions, like measles immunizations. These results are congruent with the Daku et al. (2012) study that found children had higher vaccination rates in countries with longer duration of maternity leave and higher income replacement while on maternity leave. Conversely, MCV2 had a positive and significant relationship with measles counts. This surprising finding may be explained with the variability in the timing of the second dose of measles vaccine between countries, or that countries with high measles rates respond by increasing the second dose of measles vaccine. Our finding that GDP had the largest influence on the model in comparison to the other variables is congruent with expectation that development improves health outcomes (Patterson \& Veenstra, 2016). Therefore, GDP may be an important control variable to include in research that investigates how welfare spending influences health interventions.

\subsection{Strengths and Limitations}

This study's primary strength is that it uses methods that consider geography and time. This study includes all 
countries for which data is available, making the sample as close to the population as possible. The study uses data over time to decrease the influence of temporal ambiguity and account for history. Furthermore, this study used previous research to inform the selection of control variables.

A limitation of any study that includes country level analysis is the lack of consideration toward within-country variation. Furthermore, research at the country level may fail to account for supra-national influences, like globalization, neoliberalism, and multinational corporations. Further challenges to country-level studies include differences in the quality and methods of data collection between countries, which may threaten validity. However, the World Health Organization attempts to verify the accuracy of their data with the reporting process described above. Furthermore, the use of quantitative methods to analyze abstract ideas and policy nuances is another challenge to this study. Finally, because this is an ecological, correlational study, and no causality can be determined from its results. However, despite these limitations, the strengths of the study make it a valuable addition to the nursing and health literature.

\section{Conclusion}

This research has uncovered some valuable insights that have the potential to inform public policy decisions about primary prevention and welfare spending. Our findings suggesting that national welfare spending may have an influence on the relationship between measles immunizations and measles infection. While these results require further research, they suggest that welfare spending may have a beneficial impact on prevention interventions, like immunizations. Therefore, welfare spending policies have the potential to significantly impact people's health.

\section{Competing Interests Statement}

The authors declare that there are no competing or potential conflicts of interest.

\section{References}

Borrell, C., Palencia, L., Muntaner, C., Urquia, M., Malmusi, D., \& O'Campo, P. (2014). Influence of macrosocial policies on women's health and gender inequalities in health. Epidemiologic Reviews, 36(1), 31-48. http://dx.doi.org/10.1093/epirev/mxt002

Center for Systemic Peace. (2017). INSCR data page. Retrieved from http://www.systemicpeace.org/inscrdata.html

Daku, M., Raub, A., \& Heymann, J. (2012). Maternal leave policies and vaccination coverage: A global analysis. Social Science and Medicine. http://dx.doi.org/10.1016/j.socscimed.2011.10.013

Esping-Andersen, G. (1990). The three worlds of welfare capitalism. Princeton, N.J.: Princeton University Press. https://doi.org/10.1177/095892879100100108

Esping-Andersen, G. (1999). Social foundations of post-industrual economies. Oxford, UK: Oxford University Press. https://doi.org/10.1093/0198742002.001.0001

Esping-Andersen, G. (2009). Incomplete revolution. Cambridge, UK: Polity Press.

Ferrarini, T. (2006). Families, states, and labour markets: Institutions, causes, and consequences of family policy in post-war welfare states. Cheltenham, UK: Edward Elgar Publishing. https://doi.org/10.4337/9781847201669

Gelman, A., \& Rubin, D. B. (1992). Inference from iterative simulation using multiple sequences. Stat Sci, 7 , 457-472. https://doi.org/10.1214/ss/1177011136

Geweke, J. (1992). Ealuating the accuracy of sampling-based approaches to calculating posterior moments. In J. Bernardo, J. Berger, A. Dawid, \& A. Smith (Eds.), Bayesian statistics 4, fourth Valencia international meeting, 1991 (pp. 163-193). Oxford University Press. https://doi.org/10.21034/sr.148

Heidelberger, P., \& Welch, P. D. (1981). A spectral method for confidence interval generation and run length control in simulations. Commun ACM, 24, 233-245. https://doi.org/10.1145/358598.358630

IBM Corporation. (2012). IBM knowledge center - generalized linear mixed models. Retrieved from http://www-01.ibm.com/support/knowledgecenter/SS3RA7_15.0.0/com.ibm.spss.modeler.help/idh_glmm.h tm

IBM Corporation. (2016). IBM SPSS statistics for windows (Version 24.0). Armonk, NY: IBM Corp.

International Labour Organization. (2017). World social protection report 2017-19: universal social protection to achieve the sustainable development goals. Retrieved from Geneva, Switzerland: http://www.socialsecurityextension.org/gimi/gess/RessourcePDF.action?ressource.ressourceId=54887 
Jorm, A. F., \& Ryan, S. M. (2014). Cross-national and historical differences in subjective well-being. International Journal of Epidemiology, 43(2), 330-340. https://doi.org/10.1093/ije/dyt188

Marshall, M. G., Gurr, T. R., \& Jaggers, K. (2017). Polity IV project - political regime characteristics and transitions, 1800-2016 - data users' manual. Retrieved from http://www.systemicpeace.org/inscr/p4manualv2016.pdf

Ng, E., Muntaner, C., \& Chung, H. (2016). Welfare states, labor markets, political dynamics, and population health: A time-series cross-sectional analysis among east and southeast asian nations. Asia-Pacific Journal of Public Health, 28(3), 219-231. https://dx.doi.org/10.1177/1010539516628171

Patterson, A. C., \& Veenstra, G. (2016). Politics and population health: Testing the impact of electoral democracy. Health and Place, 40, 66-75. https://doi.org/10.1016/j.healthplace.2016.04.011

Raftery, A. E., \& Lewis, S. (1992). How many iterations in the Gibbs sampler? In J. Bernardo, J. Berger, A. Dawid, \& A. Smith (Eds.), Bayesian statistics 4, fourth Valencia internatonal meeting, 1991 (pp. 763-773). Oxford University Press. https://doi.org/10.21236/ADA640705

Raphael, D. (2013). The political economy of health promotion: Part 2, national provision of the prerequisites of health. Health Promotion International, 28(1), 112-132. http://dx.doi.org/10.1093/heapro/dar058

RStudio Team. (2016). RStudio. Boston, MA, USA: RStudio Inc. Retrieved from http://www.rstudio.com/

SAS Institute Inc. (2020). SAS Studio. Cary, NC, USA: SAS Institute Inc.

Shahidi, F. V., Siddiqi, A., \& Muntaner, C. (2016). Does social policy moderate the impact of unemployment on health? A multilevel analysis of 23 welfare states. European Journal of Public Health, 26(6), 1017-1022. https://doi.org/10.1093/eurpub/ckw050

Spiegelhalter, D., Thomas, A., Best, N., \& Lunn, D. (2014). OpenBUGS Version 3.2.3.

The World Bank Group. (2017a). Gender statistics - databank. Retrieved from http://databank.worldbank.org/data/reports.aspx?source=gender-statistics\#

The World Bank Group. (2017b). World development indicators - databank. Retrieved from $\mathrm{http}: / /$ databank.worldbank.org/data/reports.aspx?source=2\&series=SI.POV.GINI\&country=

United Nations. (2015). The millennium development goals report 2015. Retrieved from http://www.un.org/millenniumgoals/2015_MDG_Report/pdf/MDG\%202015\%20rev\%20(July\%201).pdf

United Nations. (2017). UNSD - Methodology. Retrieved from https://unstats.un.org/unsd/methodology/m49/

World Health Organization. (2016). GHO - visualizations - indicator metadata registery. Retrieved from http://apps.who.int/gho/data/node.wrapper.imr?x-id=4756

World Health Organization. (2017). WHO - data, statistics, and graphics: immunizations, vaccines, and biologicals. Retrieved from http://www.who.int/immunization/monitoring_surveillance/data/en/

\section{Copyrights}

Copyright for this article is retained by the author(s), with first publication rights granted to the journal.

This is an open-access article distributed under the terms and conditions of the Creative Commons Attribution license (http://creativecommons.org/licenses/by/4.0/). 